\title{
A ARQUITETURA MODERNA E O CONDEPHAAT NO DESAFIO DAS PRÁTICAS SELETIVAS
}

FLÁVIA BRITO DO NASCIMENTO UNIVERSIDADE DE SÃO PAULO, SÃO PAULO, SÃO PAULO, BRASIL

Doutora pela Faculdade de Arquitetura e Urbanismo da Universidade de São Paulo (FAU-USP). Docente na graduação e pós-graduação da mesma instituição.

E-mail: flaviabn@usp.br

DOI

http://dx.doi.org/10.11606/issn.1980-4466.v13i26espp116-140 


\section{A ARQUITETURA MODERNA E O CONDEPHAAT NO DESAFIO DAS PRÁTICAS SELETIVAS \\ FLÁVIA BRITO DO NASCIMENTO}

\section{RESUMO}

O presente artigo discute a proteção à arquitetura moderna pelo Conselho de Defesa do Patrimônio Histórico, Artístico, Arqueológico e Turístico (Condephaat) do Estado de São Paulo em perspectiva histórica, procurando problematizar a compreensão de modernidade e as atribuições de valor à arquitetura do século XX. Trataremos neste artigo das ações que o órgão estadual paulista fará quanto aos bens imóveis modernos discutindo sua relação com o legado discursivo da historiografia da arquitetura. Entendendo que a arquitetura moderna é parte integrante dos cânones do patrimônio nacional, pergunta-se em que medida o moderno no órgão estadual paulista foi capaz de romper a lógica do foco na arquitetura vista a partir da crítica e de seus atributos estéticos ou estilísticos. Debateremos o papel da tradição do grupo de arquitetos modernos nas práticas na valoração das obras modernas paulistas, compreendendo de que maneira as progressivas mudanças no patrimônio nos anos 1970, e claramente nos anos 1980, trarão para a preservação da arquitetura moderna na ação do órgão estadual paulista, chegando até os tombamentos mais recentes nos anos 2000.

\section{PALAVRAS-CHAVE}

Arquitetura moderna. Condephaat. Políticas públicas. Patrimônio arquitetônico. 


\title{
MODERN ARCHITECTURE AND CONDEPHAAT AT SELECTIVES PRACTICES CHALLENGER \\ FLÁVIA BRITO DO NASCIMENTO
}

\begin{abstract}
This article describes the protection of modern architecture by Conselho de Defesa do Patrimônio Histórico, Artístico, Arqueológico e Turístico (Condephaat) from a historical perspective and aims to problematize the understanding of modernity and the ascription of value to twentieth-century architecture. In this article, we address the actions taken by the São Paulo State heritage protection agency with regards to modern buildings, discussing what was understood as modern, as well as its relation to the discursive legacy of the modern architecture historiography. Understanding that modern architecture is an integral part of the accepted canons of national heritage, we question to what extent Condephaat's approach to modern architecture managed to shift from the logic of an idea of architecture that is based on critique and its aesthetic or stylistic attributes. We will discuss the role of the tradition of the group of modern architects in the ascription of value to modern São Paulo architecture, and to achieve an understanding of how the progressive changes to the heritage field in the 1970s, and clearly in the 1980s, affected the preservation of modern architecture by Condephaat, until the recent listings in 2000 s.
\end{abstract}

\section{KEYWORDS}

Modern architecture. Condephaat. Heritage preservation. Architectural heritage. 


\section{OS MODERNOS E A ORTODOXIA DO PATRIMÔNIO: O CASO} PAULISTA E SUAS LÓGICAS DISCURSIVAS

A preservação da arquitetura moderna no Brasil remonta à construção das políticas de preservação pelo atual Instituto do Patrimônio Histórico e Artístico Nacional (Iphan), iniciadas em $1937^{1}$. Numa história já consagrada pela historiografia (RUBINO, 1996; CHUVA, 2009), o grupo de intelectuais ligados ao modernismo encontra espaço no aparato estatal varguista $\mathrm{e}$ passa a ter no Ministério da Educação e Saúde Pública locus privilegiado de interlocução e realização. O esforço de afirmação da arquitetura moderna e de busca por hegemonia intelectual no Brasil esteve, em certos aspectos, vinculado ao espaço que os arquitetos modernos tiveram no interior do órgão de preservação. A partir de 1946, quando o Ministério da Educação e Saúde Pública - marco inaugural do movimento - é tombado logo após a inauguração, ficam claras as relações operativas entre a preservação e a historiografia. Até a década de 1960, os tombamentos do moderno no Brasil atenderam a esses propósitos e as práticas seletivas, servindo, para além da preservação, como instância de autoconsagração. E obras como Igreja

\footnotetext{
1. As políticas de preservação do patrimônio cultural no Brasil têm início antes da criação Serviço do Patrimônio Histórico e Artístico Nacional (Sphan), por meio de alguns decretos e projetos de lei e também da Inspetoria de Monumentos Nacionais, criada em 1934, no Museu Nacional (MONTENEGRO, 2015; PINHEIRO, 2017).
} 
da Pampulha, Estação de Hidroaviões, Parque do Flamengo, Catedral de Brasília foram tombadas (NASCIMENTO, 2016b, Cap. 2).

Até os anos 1960, os tombamentos do moderno no Brasil seguiram atendendo a critérios estéticos na valoração. Na década de 1970, momento de significativas transformações no campo do patrimônio no Brasil e no exterior, assiste-se a uma interrupção de reconhecimentos que será retomada nos anos 1980, seja pelo Iphan, seja pelos órgãos estaduais fundados, também, para atender à expansão do campo de configuração de identidades regionais e de compartilhamento da gestão em uma estratégia do governo federal. Embora já existissem órgãos estaduais de preservação desde os anos 1940, será ao longo dos anos 1960 e início dos anos 1970 que o patrimônio oficial deixará de ser tarefa exclusiva do Iphan. Nesses anos, são criados diversos órgãos estaduais e locais de preservação, por razões diversas, entre as quais as políticas nacionais do regime militar, que passou a estimular a regionalização da tarefa do patrimônio, clara nos documentos que resultaram dos Encontros de Governadores em 1970 e 1971 (NASCIMENTO, 2016a).

Embora este seja um assunto a ser mais bem investigado, sabe-se que muitas das ações dos órgãos estaduais criados nos 1970 atendiam a demandas do planejamento mais geral do Iphan e do Ministério do Planejamento. No caso do Condephaat, criado em 1969, pouco antes da deliberação explícita do compartilhamento de funções feita nos encontros de governadores, houve uma clara proximidade com o Iphan, especificamente por intermédio do arquiteto Luiz Saia, Superintendente da Regional de São Paulo. Segundo Marly Rodrigues (200o, p. 61-64), não se rompeu com a "ortodoxia do Iphan" nesse momento inicial, atendendo-se, também, a interesses de certa elite paulista de se ver representada e perpetuada. Até meados da década de 1970, o Condephaat trabalhou com atenção aos critérios regionais e suas representações materiais, característicos das épocas socioeconômicas bem demarcadas, conforme seus "ciclos", pautados no culto nostálgico ao passado e na concepção de cultura como erudição. A partir de 1975, algumas mudanças ficam claras, como a atenção especial à proteção do patrimônio natural e também o progressivo atendimento às demandas da sociedade civil (SCIFONI, 2006, p. 132). É nesse momento que a arquitetura moderna aparece nas práticas de valoração. Os tombamentos intensificam-se no final dos anos 1970 e ao longo dos anos 1980, momento de efervescência 
democrática no patrimônio, em que o órgão terá ações decisivas de ampliação do escopo da preservação no Brasil, quer seja mudando os objetos de valoração, quer seja nas formas de atuação. Foi nesse período que o legado da arquitetura moderna esteve em pleno debate nacional e internacional, do qual o Condephaat não deixou de participar.

A partir de então, a arquitetura do século XX será objeto de interesse do órgão estadual de preservação. Aos tombamentos federais - os quais se intensificarão nos anos 1980 -, se somarão os dos órgãos estaduais, sendo os mais atuantes nessa esfera justamente os estados que foram "berço" das "escolas", o Instituto Estadual do Patrimônio Cultural (Inepac) no Rio de Janeiro e o Condephaat em São Paulo. Entendendo que a arquitetura moderna é parte integrante dos cânones do patrimônio nacional, pergunta-se em que medida o moderno no órgão estadual paulista foi capaz de abolir a lógica do foco na arquitetura vista a partir da crítica e de seus atributos estéticos ou estilísticos. De que maneira as progressivas mudanças no patrimônio nos anos 1970, e claramente 1980, trarão para a preservação da arquitetura moderna na ação do órgão estadual paulista?

\section{O CONDEPHAAT E A CHEGADA DO MODERNO}

Segundo Smith (2006, p. 26-27), a Carta de Veneza de 1964 é o texto canônico da história moderna do patrimônio cultural e de suas práticas, reforçando certos princípios, como o papel dos especialistas na valoração. Na sequência da Carta, virão diversas mudanças e novos atores, como a Unesco e a preservação dos bens mundiais, a preocupação com o meio ambiente e a defesa do cotidiano ou não monumental. No caso brasileiro, embora houvesse conhecimento das cartas e decisões internacionais - sendo o Brasil um dos signatários da Carta de Veneza -, elas serão vividas de maneira ambígua. O ano da Carta de Veneza é o do golpe militar que alteraria duramente os direitos civis. Sobretudo a partir do final dos anos 1960, o patrimônio será objeto de interesse como política de desenvolvimento ou de reforço de identidades nacionais, seja em nível federal, seja em nível local. A criação de novos órgãos de preservação em diversos estados e a construção de políticas municipais de planejamento com atenção ao patrimônio são reveladoras do interesse que o patrimônio passa a ter no período. Ao mesmo tempo em que os órgãos estaduais serão criados no contexto do regime autoritário e, 
sob alguns aspectos, por interesse das elites, por outro lado, sua atuação possibilitará novas práticas. Embora os órgãos estaduais tragam novidades tipológicas e arquitetônicas, eles continuaram a reiterar as lógicas da preservação nacionais focadas na arquitetura, de acordo com a avaliação de Lia Motta (2000). Novas linguagens são admitidas, como o eclético e o moderno, mas as maneiras e os critérios pouco se transformaram, salvo algumas exceções.

Nos anos 1970, as ações mais inovadoras do ponto de vista das práticas e das atribuições de valor estiveram por conta dos municípios que, por meio de planos diretores e das políticas de planejamento, fizeram reconhecimentos de bens imóveis mais ligados aos processos urbanos e ao cotidiano, como é o caso de São Paulo (no inventário da Cogep - Coordenadoria Geral de Planejamento) e do Rio de Janeiro (no Plano Urbanístico Básico e, depois, no Corredor Cultural) ${ }^{2}$. No que se refere ao Iphan, as políticas de patrimônio terão bastante fôlego e interesse nos anos 1970, embora sejam reiterados os compromissos com as práticas discursivas do Estado Novo, em que o monumental e o colonial serão objeto de constituição de identidades nacionais. (CORREA, 2016; NASCIMENTO; MARINS, 2016).

No Condephaat, a nova agenda de preservação que passaria a circular desde os anos 1970, floresceria com a redemocratização. E é justamente um bem moderno que será protagonista destes novos ares de aproximação com os sujeitos sociais, da incorporação dos movimentos sociais urbanos e da preservação pautada para além dos critérios estético-estilísticos, agendas dos anos 1980.

A Casa Modernista foi construída pelo arquiteto para sua própria família no final dos anos 1920, em meio a um imenso jardim, onde viveu por cerca de 40 anos. No final dos anos 1970 a casa ficou vazia e, em 1983, os herdeiros deram início à venda da casa e do terreno para uma imobiliária. O empreendimento Palais Versailles, com quatro torres de apartamentos, ocuparia boa parte do terreno, impedindo o uso do jardim que era feito pelos moradores do bairro. Diante disso, uma intensa mobilização dos moradores do bairro da Vila Mariana e de estudiosos se iniciou para

2. Para o papel dos municípios e do planejamento urbano nos anos 1970 ver Stival, 2017; Tonasso, 2017; Nascimento, 2018. 
impedir a destruição da casa e salvaguardar a área verde ao redor. Esta se fundava nas possibilidades de valoração da arquitetura pelos seus aspectos simbólicos ou afetivos para a população, os quais motivaram a luta por sua manutenção, menos da casa por seus valores arquitetônicos, mas da importante área verde. O grupo foi organizado em torno do Movimento Pró-preservação do Parque Modernista, que empreendeu muitos esforços para a salvaguarda da casa e jardins (NIGRO, 2001).

Às vésperas do ano novo de 1984, o então diretor do Condephaat, Antônio Augusto Arantes, abriu o processo de tombamento da Casa Modernista, na Vila Mariana, projetada por Gregori Warchavchik, que estava sob ameaça de demolição para a construção de edifícios residenciais, garantindo o seu tombamento em caráter provisório. Os acalorados debates pela preservação da casa envolveram moradores do bairro, políticos, universidades e interessados em episódios que tiveram passeatas, confrontos com a polícia, duras argumentações com os proprietários e processos judiciais. Abaixo-assinados da comunidade e pareceres de especialistas fundamentaram o processo de tombamento aprovado pelo Conselho Consultivo do Condephaat em 1984 (NIGRO, 2001).

O tombamento do Instituto Caetano de Campos, em 1976, localizado no centro de São Paulo, já havia sido um precedente importante dos contatos com a sociedade civil. O Condephaat respondeu rapidamente e a contento ao clamor por sua preservação, impedindo a sua demolição pela passagem do metrô. A imagem positiva que $\mathrm{o}$ ato alcançou na sociedade e a abertura política dos anos 1980 criaram um ambiente de maior permeabilidade e visibilidade em que o Condephaat passou a atender, cada vez mais, aos pedidos da sociedade. Segundo Paulo Garcez (2008), a chamada "política de balcão" foi se estabelecendo a partir dos anos 1980, em que os processos eram abertos por demanda do público. As políticas patrimoniais foram sendo ditadas muito mais pela prática do que pela sistematização de critérios e procedimentos seletivos organizados a priori.

Embora o Condephaat estivesse mais permeável às demandas, a proteção da Casa Modernista de Warchavchik foi uma exceção entre os bens imóveis ligados ao movimento moderno no que se refere à relação com a sociedade civil organizada. A valoração da arquitetura moderna veio, mormente, por interesse dos saberes técnicos e, assim como no Iphan, do 
grupo de arquitetos modernos protagonistas ou ligados a eles. A praxe não foi a da motivação por interesse público, mas a reiteração das lógicas de autoconsagrarão e de celebração dos monumentos modernos. A maior parte dos tombamentos de bens culturais do chamado "patrimônio moderno" recaiu sobre obras consagradas pela matriz interpretativa da história escrita por professores da Faculdade de Arquitetura e Urbanismo da Universidade de São Paulo (FAU-USP), ou seja, aquela ligada aos debates do "movimento moderno". Como já dito em outras oportunidades, há uma clara relação entre escrita da história e preservação no Brasil (NASCIMENTO, 2016b, Cap. 2). Os estudos dos especialistas fundamentaram o saber especializado e deram estrutura e densidade às práticas de valoração. Especialmente no que diz respeito à arquitetura do século XX, a maior parte das proteções recaiu sobre a arquitetura ligada ao que Martins chamou de "trama narrativa" da arquitetura moderna. Trata-se de uma matriz de leitura que se tornará recorrente na historiografia inaugurada pelo livro e pela exposição homônima Brazil Builds, para além de detonar uma onda internacional de divulgação da arquitetura moderna nacional que estruturou a ideia de indissociabilidade entre a originalidade da arquitetura brasileira e sua identificação com a articulação entre modernidade e tradição, sustentada pela necessidade de afirmação ideológica do aparato estatal varguista (MARTINS, 1999; TINEM, 2006).

Interessante observar que da listagem de bens tombados pelo Condephaat construídos no século XX, alguns fogem à filiação da linguagem do chamado movimento moderno, como o Estádio do Pacaembu, o Edifício Saldanha Marinho, de Elisário Bahiana, representativos do que se chamou art dèco, e o Teatro São Vicente, em Assis, do final dos anos 1940, protegido por sua importância afetiva, cultural e histórica, não tendo importado a "ausência de qualquer valor artístico intrínseco". Ou seja, os critérios estéticos não foram os mais relevantes (CONDEPHAAT, 1986). $\mathrm{O}$ que se percebe com a inclusão de outros bens do século XX além dos ligados ao "movimento moderno" é a possibilidade de valoração que supera critérios da arquitetura. Os valores históricos e afetivos encontram lugar, tornando complexa a atribuição de valor.

Mas, de modo geral no Condephaat, os cânones do Iphan no patrimônio e a consagração historiográfica guiaram os primeiros pedidos de 
proteção à arquitetura moderna que vieram dos conselheiros, arquitetos ou sociedades de classe e assinados por personalidades ilustres da arquitetura. A ameaça da perda, a confirmação da história da arquitetura, os argumentos de pioneirismo e ineditismo foram fundantes num primeiro momento que perpassa a década de 1970 até os anos 1980. A retórica da perda, na expressão de José Reginaldo Gonçalves (1996), muitas vezes apressou e fundamentou as proteções.

Com efeito, o primeiro pedido de tombamento do moderno foi iniciativa do representante do Iphan no Conselho, o arquiteto Luiz Saia. O pedido feito em 1973 solicitava a proteção da casa de Flávio de Carvalho, recém-falecido, localizada no município de Valinhos (CONDEPHAAT, 1973). O processo ficou em aberto até 1981, quando outros edifícios modernos vieram à pauta no Conselho, colocando em discussão os critérios de seleção. Para Antônio Luis Dias de Andrade, conselheiro e professor da FAU-USP que sucedeu Saia na direção da regional do Iphan em São Paulo, a justificativa favorável era o papel de vanguarda exercido por Flávio de Carvalho e a inexistência de obras íntegras do autor. O conselheiro ressaltava a atenção do Condephaat às obras fora do escopo dos "bens culturais ditos consagrados", mas cujo significado era inegável. (CONDEPHAAT, 1981).

Não é por acaso que o pedido de proteção à casa de Flavio de Carvalho só se concluiu no começo dos anos 1980, quando acontece um movimento mais amplo de valorização historiográfica da arquitetura moderna brasileira e de construção de sua memória. A percepção de passado do moderno era um fato incontornável destes anos. Na medida em que, minimamente, as realizações dos arquitetos modernos distanciaram-se no tempo e seus personagens deixam de fazer parte da lida cotidiana do patrimônio, e que se esboçam as críticas às suas obras, percebemos movimentos de valorização do seu legado. Periódicos especializados e órgãos de patrimônio se debruçaram sobre as obras, textos, projetos e arquitetos, muitos na chave do que se afirmou no debate Arquitetura hoje, promovido pela editora Projeto em 1982: "as realizações do modernismo já fazem parte de nosso patrimônio cultural, do qual somos depositários” (FRACINO, 1982, n. 42).

Muito sintomático das valorações do moderno e do modo como os órgãos de patrimônio agiram em consonância com o sentimento mais de geral de historicização é o tombamento da FAU-USP, o primeiro do 
movimento moderno a se realizar no Condephaat. Ruy Othake, então presidente do Conselho, pede com a máxima urgência o tombamento do edifício em razão da realização do $1^{\circ}$ Arquimemória, em 1981. Afirma que o reconhecimento de edificações contemporâneas é o programa que o Conselho deverá desenvolver pelos valores arquitetônicos e socioeconômicos e de paisagem urbana de tais obras. A FAU, como exemplar destacado no quadro da arquitetura contemporânea paulista, por transparecer o programa de ensino para o qual foi projetado, por seus avanços tecnológicos e pela implantação, merecia o reconhecimento. $\mathrm{O}$ relator do processo foi Eduardo Corona, conselheiro pela FAU-USP, que pontuou o oportuno de o edifício ser o ensejador da proteção às obras "contemporâneas", já que em São Paulo encontrava-se um rol de edificações construídas a partir dos anos 1920 com valores artísticos e técnicos que os condicionavam como cultura e como história. Embora questionando a ausência de critérios "lógicos e razoáveis" para o estudo da arquitetura contemporânea, aprova o tombamento da Faculdade e sugere a organização em curto espaço de tempo dos critérios desejados para a análise de tais obras (CONDEPHAAT, 1981). A FAU de Artigas alcançava a condição de patrimônio paulista por ação da comunidade acadêmica que nela se reconhecia. Com pouco mais de dez anos de inaugurada, tinha lastro simbólico de tal ordem que sua valoração foi inquestionável, tendo o mesmo sentido de homenagem que os tombamentos Instituto Estadual do Patrimônio Cultural (Inepac) de obras de Niemeyer e do Iphan de Lucio Costa, para citar os exemplos mais claros.

No mesmo ano do tombamento da FAU, chegam ao Conselho os pedidos do Masp (feito por Pietro Bardi) e da Sociedade Harmonia de Tênis (feito pelo Sindicato dos Arquitetos assinado por Ícaro Mello, Jon Maitrejan, Paulo Mendes da Rocha, entre outros). Num primeiro momento, para esses casos, a consagração do moderno via operatividade do tombamento é posta em dúvida. O conselheiro Corona foi de opinião firme: havia muitos arquitetos e edifícios na mesma situação, desempenhando papel importante e de destaque na "produção arquitetônica contemporânea". E segue dizendo que quanto à exceção da FAU-USP, já de valor histórico, não haveria razão do tombamento enquanto não houvesse critérios claros e definidos sobre como considerar tais obras patrimônio (CONDEPHAAT, 1981). 
Ele escreve:

Fui incumbido por V. Exa., Sr. Presidente, há algum tempo, da elaboração de alguns critérios para tombamento de obas contemporâneas. Admito que até o presente momento não consegui executar a tarefa. Ela não é fácil. Principalmente, porque há que determinar o instante no qual se deve considerar uma obra como contemporânea, cronologicamente falando, e a importância que desempenha, historicamente falando. Quando começa o rol de obras, na década de 20, na de 30 e quando acaba, na de 70 ou ontem? (CONDEPHAAT, 1981)

Corona nega os pedidos de tombamento do Masp e do Clube Harmonia. Mas o Masp volta à pauta, e é analisado por Eduardo Kneese de Mello (conselheiro também do Iphan) que o considera excepcionalidade digna de proteção, dando parecer favorável, que é aceito pelo conselho e feito o tombamento. Enquanto o Clube Harmonia ${ }^{3}$ teria que esperar os anos 1990 para o tombamento, outros tantos acontecerão nos anos 1980, na esteira das muitas celebrações e construções de memória do moderno (CONDEPHAAT, 1981). O destaque ao pioneirismo da Estação Ferroviária de Mairinque e o Edifício Esther demonstra o debate com a historiografia do movimento moderno e o papel de São Paulo, demonstrando e legando às gerações futuras obras que teriam fundando a linguagem moderna no estado e também do país. A representação da linguagem moderna paulista aparece também nos tombamentos da Casa de Vidro de Lina Bo Bardi e do Edifício Louveira de Artigas, na argumentação da importância dos autores e pelas soluções particulares e excepcionais de arquitetura no agenciamento dos espaços urbanos e na distribuição interna (WOLFF, 2007).

Ainda do lote de bens imóveis da década de 1980, cabe destacar o caso do Parque do Ibirapuera, pois difere em valoração desses últimos, já que pautado na tradição do Condephaat de estudo de áreas naturais. Os edifícios

3. O processo que fora arquivado é reaberto em 1984 diante da prerrogativa do tombamento da Casa Modernista, mas permaneceu sem estudos e guardado pelo "bom uso" enquanto outras tantas obras modernas eram tombadas pelo Condephaat (CONDEPHAAT, 1981). 
de Oscar Niemeyer não foram a motivação da proteção, mas compreendidos como parte do todo do Parque que a cidade de São Paulo recebeu como presente pelo seu $4^{\circ}$ Centenário. Seu estudo integra o conjunto de pedidos de tombamento de parques em São Paulo juntamente como o da Água Branca, o da Aclimação, o da Água Funda, o Morumbi e o da República, além da Praça Buenos Aires, feitos em 1983. Como estudou Scifoni (2006, p. 138-139), o processo do Ibirapuera só foi aberto em 1987 quando as obras do Túnel Ayrton Senna, sob o Parque do Ibirapuera, geraram muita polêmica, acirradas pela oposição ferrenha do prefeito Jânio Quadros ao tombamento. A justificativa voltava-se para o valor do Parque, em que se incluía o valor das obras de Niemeyer, e não as obras em si, o que demonstra a expansão e complexificação da prática preservacionista do Condephaat no período chamado por Simone Scifoni de "tempos progressistas". Importante observar que, embora as áreas naturais tenham sido a motivação primeira da proteção, nas ações de salvaguarda do bem tombado, recorrentemente afirma-se o valor dos edifícios de Niemeyer como se fossem a motivação, e não parte do parque (SCIFONI, 2006).

Os anos 1980 foram muito importantes para a atribuição de valor aos bens culturais no Brasil, quando houve uma efetiva ampliação dos cânones. Quanto à arquitetura moderna, não foi uma fronteira conquistada do ponto de vista das práticas. Tanto no Rio de Janeiro, como em São Paulo, serão mobilizadas as elaborações historiográficas da intelectualidade da arquitetura na elaboração de estudos de tombamento. A excepcionalidade da arquitetura e, principalmente a autoria, segundo Silvia Wolff (2007), contou nos tombamentos de edifícios modernos pelo Condephaat muito mais do que no das arquiteturas de outros períodos. A vinculação das obras aos arquitetos famosos da Escola Paulista, assim citada, aliada às características técnico-construtivas será motivação para as proteções de muitas das obras. Mesmo que os "critérios" ou uma "listagem de bens passíveis de tombamento" nunca tenham sido elaborados, os tombamentos atenderam a dado perfil de arquitetura moderna; qual seja, aquela estabelecida pela linha de interpretação sacramentada pela história da arquitetura escrita e ensinada a serviço do projeto, com caráter operativo. O discurso histórico desde os anos 1960 e 1970 se dará instrumentalizando-se a prática projetual estabelecida no plano de ensino de Artigas, o que aparecerá nas indicações 
e pareceres dos conselheiros e técnicos ligados a ela ${ }^{4}$. As motivações e justificativas para a seleção da arquitetura moderna a preservar veio dos saberes da arquitetura.

Mesmo na preservação da Casa Modernista, que representou as possibilidades de valoração da arquitetura pelos seus aspectos simbólicos ou afetivos, os quais motivaram a luta por sua manutenção, os valores arquitetônicos foram igualmente mobilizados. A novidade maior da preservação da casa de Warchavchik estava mais nos métodos e menos no objeto em si, ainda que os jardins tenham sido incluídos como parte integrante. Preservou-se não uma casa como tantas outras da Vila Mariana, mas a icônica Casa Modernista, exaltada por certa historiografia paulista como gênese do movimento nacional. Esses aspectos pesaram decisivamente em muitos dos pareces técnicos de tombamento.

\section{O MODERNO SE INSTITUCIONALIZA: OS SABERES TÉCNICOS E AS NOVAS RELAÇÕES COM A HISTORIOGRAFIA DA ARQUITETURA}

A partir dos anos 1990, a proteção ao moderno era um fato no Brasil. Seja pelo Iphan, seja pelos órgãos estaduais, a percepção de memória do moderno deixou de ser alvo de disputa para ser objeto de pesquisa acadêmica. Se a casa Warchavchik havia marcado o ciclo de tombamentos de bens moderno de modo vanguardista nos anos 1980, a perda da Fábrica Duchen, no início da década de 1990, mostrava a complexidade da atribuição de valor aos bens culturais do século XX, o papel dos autores e a pressão da iniciativa privada. A fábrica chegou a ter o pedido de tombamento aprovado pelo Conselho e reiterado após manifestação dos proprietários contrários à proteção legal, apoiados pelo autor do projeto, Oscar Niemeyer. Obras irregulares causaram graves danos à estrutura dos edifícios, numa inexplicada ação de demolição. Em 1992, diante da inexistência do bem cultural, o tombamento foi cancelado (OKSMAN, 2017, p. 81-89).

A criação do Docomomo Internacional em 1989 e do seu Comitê Brasileiro em 1992, sediado na Universidade Federal da Bahia sob a

\footnotetext{
4. Anotações do curso AUH 5859 - Projeto Moderno: Historiografia e Crítica, ministrada pelo professor José Tavares Correia de Lira, FAU-USP, $1^{\circ}$ semestre 2008.
} 
coordenação de Anna Beatriz Ayrosa Galvão, trouxe progressivo interesse ao legado do moderno. O primeiro Seminário Internacional em Brasília levou ao estabelecimento de redes que não pararam de se multiplicar após os anos 200o. Os seminários do Docomomo Brasil agregaram o interesse pela arquitetura do movimento moderno no Brasil e fomentaram o aumento das pesquisas. Desde o primeiro Seminário Nacional em Salvador, em 1992, aconteceram inúmeros seminários nacionais, além de diversos outros regionais. A arquitetura moderna ganhou interesse particular em São Paulo, seja pelo fato de o Docomomo ter atuado em cooperação com o Departamento do Patrimônio Histórico de São Paulo, órgão municipal de preservação, seja pelo fato de o Estado congregar muitos estudiosos e especialistas no tema em torno de programas como a Pós-graduação em Arquitetura e Urbanismo da Universidade de São Paulo. Nessa década, o interesse acadêmico gerou inúmeros trabalhos monográficos sobre arquitetos, instituições, edifícios e personagens mostrando o feixe de concretizações da arquitetura brasileira no século XX.

Os pedidos de tombamento de bens do movimento moderno feitos ao Condephaat nos anos 1990 seguiram o foco das homenagens às individualidades. Contudo, as respostas do órgão de preservação às demandas tenderam a ampliar o escopo de compreensão à obra dos arquitetos e de suas produções. Esse é o caso dos pedidos de tombamento da produção dos arquitetos Rino Levi e Vilanova Artigas, em que o conjunto das obras foi estudado (CONDEPHAAT, s. d.; CONDEPHAAT, 2010). E, a partir de critérios estabelecidos, foi feita a seleção das obras a serem tombadas. O tema dos critérios de seleção do moderno foi recorrente nas respostas aos pedidos de tombamento, desde que ficou clara a extensão das obras que poderiam ser preservadas. As hesitações às preservações do moderno, quando existiram, recaíam não sobre a certeza do que deveria ser tombamento, mas em relação à extensão do que seria possível preservar e às dificuldades de exclusão e seus critérios. Mas o atendimento à demanda por critérios se fez nos tombamentos mais recentes das obas modernas, diante da extensão da tarefa, do comprometimento do corpo técnico com as práticas seletivas, aliados às inúmeras dificuldades crônicas dos órgãos de preservação, que resultaram em exclusões.

O pedido de tombamento da obra de Rino Levi que chegou ao Condephaat em 1995 estava, segundo o estudo técnico, "longe de constituir 
unanimidade". As produções nacional e paulista eram questionadas em face dos estudos sobre o seu lugar na produção paulista. Entre Warchavchik e a passagem de Oscar Niemeyer no estado até a configuração da Escola Paulista, quais seriam as características desta produção? Do momento em que é feito o pedido até o encaminhamento dos estudos nos anos 2000, há um crescimento dos estudos monográficos de arquitetos paulistas que reconfiguram o quadro de compreensão de sua obra e tornam a preservação um fato possível (UPPH-GEI, s. d.). Novamente, a proposta de tombamento estará fundamentada na historiografia da arquitetura, cujos livros de Hugo Segawa (1998) e, sobretudo, de Renato Anelli (2001), tornaram-se importantes crivos de legitimidade. O diálogo de inserção da obra de Rino Levi parecia ser o de certos panoramas como o de Carlos Lemos (1978) para a revista CJ Arquitetura em 1978. Neste, a arquitetura paulista era definida de Ricardo Severo a Vilanova Artigas e, entre eles, Warchavchik e alguns estrangeiros. A nova historiografia do momento dos revisionismos trazia novos autores e atores à cena, fazendo ainda mais complexo o desafio seletivo da preservação.

O fôlego e a profundidade dos estudos técnicos reunidos no Dossiê Rino Levi (CONDEPHAAT, s. d.) - além do detalhado parecer técnico, cada bem cultural recebeu uma ficha de identificação - demonstram a intenção de estabelecer critérios, olhando o conjunto da produção do arquiteto, na perspectiva de indicar os bens à preservação. Tais critérios foram guiados pela representação tipológica dos bens, de modo que diversos programas estivessem presentes na lista. Mas, ao que nos parece, a diretriz maior foi aquela de que as edificações fossem "exemplares significativos da arquitetura moderna”. Por significativo, entendem-se as contribuições estéticas ou plásticas e técnicas que dada arquitetura poderia dar na consideração do conjunto da obra. Ao mesmo tempo, o atestar destes atributos - frequentemente adjetivados como "notáveis", "superlativos" - era dado pelos estudos que recolocavam a obra de Rino Levi no quadro mais amplo das singularidades da produção arquitetônica moderna, indo além dos cânones da arquitetura que havia dado o tom das interpretações historiográficas a partir de Brazil Builds. Nos arquivamentos, tais relações entre crítica arquitetônica e seleção se evidenciam: a Gastroclínica, na Rua Silvia, foi arquivada: 
A despeito de particularidades criativas do projeto original, a concepção da clínica não foi objeto de reconhecimento pela crítica especializada em Rino Levi, nem pelos críticos e estudiosos da arquitetura moderna (UPPH-GEI, s.d.).

O tratamento em conjunto da obra do arquiteto foi desafio também pelo pedido de preservação de edifícios de Artigas. Os pedidos de tombamento chegaram nos anos 2000 ao Condephaat focados no conjunto das escolas e das passarelas, feitos pela Fundação Vilanova Artigas. Mas a estratégia do corpo técnico foi a de estudar a obra do arquiteto na sua totalidade, compreendendo suas expressões arquitetônicas de acordo com o período de sua produção, as tipologias e programas e o estado de conservação e viabilidade de preservação. As escolhas foram feitas com base no Estudo do conjunto das obras de Vilanova Artigas, estruturado na bibliografia sobre o autor (teses, dissertações, livros, catálogos de exposições). A premissa do estudo era a de que, de um lado, não era possível focar apenas em escolas e passarelas e, de outro, não era possível incluir toda a obra. O desafio de selecionar itens diante de uma obra tão extensa e constitutiva da identidade arquitetônica era complexo. Os arquitetos da Unidade de Preservação do Patrimônio Histórico (UPPH) debruçaram-se sobre a obra do arquiteto e fizeram a seleção baseados, sobretudo, na relevância historiográfica das edificações. Bens de destaque historiográfico, mas cuja preservação exigiria novas abordagens de gestão - como o Conjunto Residencial Zezinho Magalhães e a série de escolas estaduais que, inclusive, estavam no pedido inicial - ficaram de fora da listagem de bens indicados (CONDEPHAAT, 2010; MIURA, 2013).

Assim como na obra de Rino Levi, em Artigas, o amadurecimento e a capacitação do corpo técnico levaram ao aprofundamento dos estudos, com a preocupação de focar não apenas no monumento ou na excepcionalidade arquitetônica, mas pensar o conjunto da produção e suas relações urbanas (WOLFF, 2007). A apropriação do corpo técnico da tarefa da atribuição de valor está clara nestes dois processos. As escolhas são indicadas pelos saberes técnicos, e focadas nos atributos arquitetônicos (os estéticos e construtivos são ressaltados nos dois casos e como característica da arquitetura paulista), estando explícitos e conscientes, segundo afirmação de Silvia Wolff e Antônio Zagato: 
[...] é certo que a seleção de bens por sua qualidade arquitetônica pode parecer excludente, se feita em detrimento da valorização de práticas sociais de modo mais amplo. Mas é certo também que a interpretação destas escolhas não precisará, tampouco, ser limitada (WOLFF; ZAGATO, 2016).

Mas o critério da crítica arquitetônica não foi único. As escolhas também se basearam no pragmatismo da gestão, que, ao fim e ao cabo, recairia sobre a UPPH. E, portanto, segundo o Dossiê Artigas, "de um modo geral, as indicações se orientaram por evitar tombar estruturas ou construções ligadas a funções com muito dinamismo e que potencialmente sofrerão alterações significativas" (CONDEPHAAT, 2010). O caráter pragmático dessa escolha revela, também, a experiência acumulada e as limitações históricas do órgão de preservação, as quais acabaram por restringir as possibilidades de salvaguarda.

Mostrando que este era um debate sensível e que tais escolhas implicavam limitações da lista dos bens a proteger, quando o processo foi ao Conselho para apreciação, a exclusão dos bens como as escolas e passarelas foi polêmica. O conselheiro relator, arquiteto Eduardo Pereira (2011) representante do Instituto de Arquitetos do Brasil (IAB), chama a atenção para o fato de que, das 36 obras do arquiteto, somente sete estavam sendo propostas para a preservação, apenas $2 \%$ de sua produção. Ademais, os bens selecionados concentravam-se mormente na capital e arredores, deixando o interior do estado com poucas proteções. A questão colocada era a da representação do Condephaat no interior de São Paulo - argumento reforçado pela conselheira Simone Scifoni nos debates -, o que indicações para tombamento não permitiam. E, somado a isso, Eduardo Pereira fazia a crítica ao pragmatismo dos critérios, sendo inaceitável, para o relator, a exclusão pelo argumento do "ônus ao poder público" que as preservações poderiam acarretar ou mesmo pelo argumento de as preservações serem "potencialmente difíceis", e, portando, devendo ser evitadas. O conselheiro discordará de várias das exclusões da lista indicativa à preservação, solicitando a inclusão de outras tantas como as passarelas, escolas e residências (PEREIRA, 2011; CONDEPHAAT, 16/01/2012). 
Os debates no Conselho seguiram sem unanimidade, e não se aprovou inteiramente nenhuma das propostas. $\mathrm{O}$ caso retornou à pauta algumas vezes e, ao final, as sugestões de arquivamento de processos feitas pelo corpo técnico da UPPH são, grosso modo, apoiadas. O novo relator, José Luís Bizelli, apoiado nos argumentos da necessidade de seleção dos bens culturais, da observância à responsabilidade com a tarefa pública, sugere o arquivamento de 16 processos (escolas, colégios e ginásios) indicados pelo relator anterior para tombamento e indicados para arquivamento pela UPPH. E recomenda para tombamento outras três obras que não estavam na indicação inicial da UPPH, mas cujo tombamento havia sido pedido pelo relator. O que fica preservado, em conclusão, é uma listagem mais seletiva e em acordo com o que o corpo técnico havia proposto (CONDEPHAAT, 9/12/2013; BIZELLI, s. d).

O caso das obras de Artigas indica o quanto as práticas seletivas do moderno apoiaram-se nos debates internos à arquitetura. Os argumentos se concentram nas obras em si e nas lógicas da produção de um autor, descolados dos pertencimentos locais ou dos processos de urbanização em que estão imbricados. O processo do bairro de Higienópolis, na capital, traz nova perspectiva a esse debate. Fruto de longo e controverso processo com diversas abordagens e pedido de tombamento de diversas obras, ganhou forma final elaborada pelas arquitetas Silvia Wolff e Adda Ungaretti durante a gestão da professora Ana Lanna na Presidência do Condephaat. A apreciação foi feita pelo Conselho em fins de 2014, com parecer do Conselheiro do IAB (OKSMAN, 2014).

O foco do estudo é o processo de urbanização e ocupação do bairro, articulado às formas de morar, em que os palacetes ecléticos, a Praça Buenos Aires e os edifícios de apartamentos foram selecionados por um percurso nas avenidas Angélica e Higienópolis. A seleção, embora se concentre mais nos palacetes ecléticos do início do século XX, contempla edifícios de expressões arquitetônicas variadas, não importando os argumentos de filiação a determinadas linguagens (OKSMAN, 2014). Na medida em que o olhar foi urbano, e não exclusivamente arquitetônico, a seleção recaiu sobre os processos de formalização do século XX nos seus diálogos com a modernidade. Saindo, portanto, da crítica arquitetônica, importou estudar os bens que contavam a história desse processo, nas suas variadas linguagens, sem o julgamento 
específico da crítica. O protagonista é o bairro no papel que cumpriu na história urbana de São Paulo, seja como vetor de ocupação e no parcelamento das chácaras que compunham o cinturão verde da cidade e representante de modos de morar das elites no século XX, conforme a Resolução de Tombamento. Dito de outro modo, os edifícios de Rino Levi e Artacho Jurado na Avenida Higienópolis estão selecionados não pelo que representam em si para a história da arquitetura, mas pelo que são, em conjunto, para história de São Paulo, de seus processos urbanos, sociais e culturais. Entendo que a dimensão da cidade como bem cultural, e principalmente como artefato - para utilizar a proposta por Ulpiano Meneses (2006) - parece vertebrar o estudo. O bairro de Higienópolis, construído no tempo e com materializações diversas, foi compreendido como um bem cultural a ser preservado. Os edifícios, na sua dimensão urbana, contam a história dessa porção da cidade de São Paulo. Uma perspectiva diferente da tônica da preservação do moderno em que a arquitetura contava a história dela mesma - nos aspectos históricos, artísticos e construtivos - e do seu autor.

\section{CONSIDERAÇÕES FINAIS}

A "política de balcão" em que as práticas ditavam as regras foi, no Condephaat, uma tônica das ações de preservação conforme expressão cunhada por Paulo Garcez (MARINS, 2008). No que refere aos bens culturais modernos, ela pode ser considerada, também, uma possível chave interpretativa. Até as preservações das obras de Rino Levi e Artigas nos anos 2000, as proteções foram feitas em atendimento aos pedidos, sem que estudos, considerações comparativas ou sistemáticas fossem feitas. Quando o conselheiro Eduardo Corona nega o pedido do Clube Harmonia no início da década de 1980 alegando a falta de critérios e anos depois, em 1992, o caso retorna ao Conselho, o Presidente Antônio Arantes indica o tombamento, afirmando que enquanto se esperavam critérios que nunca vinham, o melhor era proteger:

A verdade é que enquanto o tempo passa e aguardamos os critérios gerais, rapidamente deteriora-se o acervo ao qual esses possíveis critérios se aplicariam. Não creio que tenhamos mais tempo a perder, mesmo porque ao que tudo indica este seria um dos bens a serem incluídos numa listagem para preservação, que ainda continua [...] (CONDEPHAAT, 1981). 
E se as políticas constroem as práticas, segundo a afirmação de Marly Rodrigues (2000), a prática foi a da preservação do que era indicado pelos herdeiros do movimento moderno em São Paulo, como o edifício da FAU-USP, do MASP, a Casa de Lina Bo Bardi. Esses herdeiros, direta ou indiretamente, estavam representados no Condephaat, seja pela FAU-USP, seja pelo Iphan, ou mesmo na Presidência do Conselho. Nomes como Luiz Saia, Carlos Lemos, Eduardo Corona e Ruy Othake tinham ligações formativas com a linguagem moderna e, no final da década de 1970 e claramente nos anos 1980, colaboram com a construção de memória e homenagens ao legado moderno por meio das indicações para o tombamento. Ou seja, a tradição moderna pesou de maneira significativa nas preservações do Condephaat.

Observa-se que à exceção da Casa Modernista - cujo objeto de interesse da população local não era a casa em si (NIGRO, 2001) -, os pedidos não vieram da sociedade civil organizada e apropriada dos bens culturais. Vieram dos herdeiros intelectuais dos autores ou dos protagonistas do movimento moderno paulista e visaram a salvaguarda de edifícios que contribuíssem para a narrativa de uma certa arquitetura moderna paulista. Assim como nas proteções do Iphan ao moderno, os estudos estiveram atrelados à construção historiográfica da arquitetura paulista, sistematizada nos anos 1980 e 1990 depois da criação do Docomomo Brasil e da significativa expansão de suas redes.

Dos anos 1990 em diante, o moderno se torna objeto de grande interesse de estudo, com os seminários sobre o tema e a proliferação dos cursos de pós-graduação em Arquitetura com inúmeras dissertações e teses sobre o movimento moderno no Brasil. A área técnica da UPPH passa a buscar critérios e sistematização dos conhecimentos, o que se relaciona com a formação dos seus quadros técnicos, levando a estudos mais aprofundados. Há nesse movimento um esforço de sistematização e construção de critérios, com clara apropriação pelos técnicos da tarefa da atribuição de valor. Os estudos tornam-se densos e extensos, não se restringindo às solicitações e indicações. No caso das obras de Artigas, o pedido solicita a preservação das passarelas e das escolas, mas o estudo técnico caminhou para a indicação de outra sorte de edifícios, selecionados a partir dos critérios arquitetônicos no estudo do conjunto da obra. 
Observa-se que o lugar do especialista em patrimônio se reforça e se legitima quando o objeto é de grande significado para a constituição do campo da preservação no Brasil. Retomo a compreensão de que a arquitetura do movimento moderno foi constitutiva da formação do campo disciplinar e das práticas de preservação no Brasil, confundindo-se, ela mesma, com as construções de nação pelo Estado Novo. Superadas em décadas esta fase de que o patrimônio histórico e artístico era articulador de uma nacionalidade homogênea, para ser compreendido na contribuição para as identidades dos grupos sociais formadores, tal como nos coloca a Constituição de 1988, cabe a pergunta: qual seria o lugar da arquitetura moderna paulista no rol dos bens tombados? E, ainda, qual seria o papel dos especialistas na sua seleção? Até aqui, esse papel tem sido o de protagonista, tendo em vista que a argumentação de valor autoral, a avaliação estética e o valor construtivo das obras dos arquitetos paulistas foram afirmações da crítica especializada que serviram como argumento para o interesse e relevância dos tombamentos. Esses recaíram, nos tombamentos feitos pelo Condephaat, excluindo-se a Casa Modernista e os bens do bairro de Higienópolis em São Paulo, numa prática - mais ou menos seletiva estruturada nos argumentos da arquitetura e de suas individualidades.

O universo potencial de preservação da arquitetura do século XX é muito grande. Em muitos lugares, tal processo de seleção tem recaído sobre as obras monumentais ou de grande legitimidade arquitetônica. Mesmo em países onde há uma suposta inflação do patrimônio, como é o clássico exemplo da França, o patrimônio moderno está sub-representado nas listagens ou parcamente protegido. Para Richard Klein (2016), sobre o caso francês, retêm-se mais facilmente as arquiteturas de caráter excepcional, conformes com os valores artísticos, que justificam considerações positivas. As descaracterizações, as transformações e os usos são aspecto de grande limitação à proteção.

Isso leva a refletir sobre a desconsideração do Conjunto Habitacional Zezinho Magalhães à preservação pelo estado de São Paulo, a expensas de sua apreciação pela crítica especializada. A dificuldade de preservação de algo "dinâmico", densamente utilizado ou mesmo transformado, levou ao arquivamento do pedido de tombamento. De um ponto de vista prático, a habitação de interesse social tem sido pouco considerada diante dos 
impasses dos usos e transformações e, também de uma ideia autenticidade, que, de modo geral, paira como uma sombra na preservação do moderno e, não somente, de sua produção habitacional (HERVOUET, 2012). Recorro a Ulpiano Meneses (2017) sobre a necessidade de repovoar o patrimônio: os exemplares de habitação seriam uma boa oportunidade de valoração da cidade como bem cultural, mas para além do artefato, colocando o habitante nos jogos de disputa e de representação do patrimônio. Caberia pensar sobre os desafios para maior diversidade tipológica, geográfica e social “dos modernos". Superando os crivos exclusivamente estético-estilísticos - ainda que possam ser importantes e válidos, como uma camada de valoração - e incluindo a participação como premissa, seria auspicioso pensar como a arquitetura a ser preservada fosse considerada não apenas nos processos urbanos, históricos, sociais (a exemplo do caso de Higienópolis), mas também nas suas fissuras e tensões.

\section{REFERÊNCIAS}

ANELLI, Renato. Rino Levi: arquitetura e cidade. São Paulo: Romano Guerra, 2001.

BIZELLI, José Luís. Parecer do conselheiro relator sobre o processo Vilanova Artigas. Condephaat, [s.d.].

CHUVA, Márcia Regina Romeiro. Os arquitetos da memória: sociogênese das práticas de preservação do patrimônio cultural no Brasil (anos 1930-1940). Rio de Janeiro: Editora UFRJ, 2009.

CONDEPHAAT. Ata n. 1657 do Conselho de Defesa do Patrimônio Histórico, Arqueológico, Artístico e Turístico do Estado de São Paulo. 16/01/2012.

CONDEPHAAT. Ata n. 1732 do Conselho de Defesa do Patrimônio Histórico, Arqueológico, Artístico e Turístico do Estado de São Paulo. 9/12/2013.

CONDEPHAAT. Processo de tombamento n. 21736/81. Faculdade de Arquitetura e Urbanismo, 1981.

CONDEPHAAT. Processo de tombamento n. 24042/86. Teatro São Vicente, 1986.

CONDEPHAAT. Unidade de Preservação do Patrimônio Histórico. Dossiê Rino Levi. São Paulo [s.d.] (mimeo).

CONDEPHAAT. Unidade de Preservação do Patrimônio Histórico. Dossiê Vilanova Artigas, UPPH n. GEI - Conjunto de Obras Vilanova Artigas. São Paulo, 2010.

CORREA, Sandra M. O Programa de Cidades Históricas: por uma política integrada de preservação do patrimônio cultural urbano. Anais do Museu Paulista, n. 24, jan./abr. 2016.

FRACINO, Tito Lívio. É preciso sacudir a poeira, criticar, discutir, se encontrar. Projeto, n. 42, jul. 1982. 
GONÇALVES, José Reginaldo Santos. A retórica da perda: os discursos do patrimônio cultural no Brasil. Rio de Janeiro: Editora UFRJ; IPHAN, 1996.

HERVOUET, Aurélie. Patrimoine et habitat social. In: KHAZNADAR, Chérif (Org.). Le Patrimoine, oui, mais quel patrimoine? Arles: Actes Sud, 2012. (Internationale de l'imaginaire Nouvelle Série, 27)

INSTITUTO DO PATRIMÔNIO HISTÓRICO E ARTÍSTICO NACIONAL. Processo de tombamento. n. 1121-T-84. Casa Modernista de Warchavchik na Rua Santa Cruz. IPHAN, 1984.

KLEIN, Richard. O legado da arquitetura do século XX: proteção administrativa versus salvaguarda efetiva. Revista CPC, n. 21 especial, p. 14-3o, $1^{\circ}$ sem. 2016.

LEMOS, Carlos. A arquitetura paulista de Ricardo Severo a Vilanova Artiga. CJ Arquitetura, n. 19, p. 14-19, 1978.

MAGALHÃES, Aline Montenegro. Inspetoria de Monumentos Nacionais (1934-1937). In: REZENDE, Maria Beatriz; GRIECO, Bettina; TEIXEIRA, Luciano; THOMPSON, Analucia (Org.). Dicionário IPHAN de Patrimônio Cultural. Rio de Janeiro, Brasília: IPHAN/DAF/ Copedoc, 2015 (verbete).

MARINS, Paulo César Garcez. Trajetórias de preservação do patrimônio cultural paulista. In: SETUBAL, Maria Alice (Org.). Terra paulista: trajetórias contemporâneas. São Paulo: Imesp; Cenpec, 2008. p. 237-326.

MARTINS, Carlos. Hay algo de irracional... Block, Buenos Aires, n. 4, p. 8-22, dez. 1999.

MENESES, Ulpiano. A cidade como bem cultural - áreas envoltórias e outros dilemas, equívocos e alcance na preservação do patrimônio ambiental urbano. In: MORI et. al. Patrimônio: atualizando o debate. São Paulo: Iphan, 2006.

MENESES, Ulpiano. Reparar o patrimônio ambiental urbano. Revista do Patrimônio Histórico e Artístico Nacional, v. 36, p. 39-52, 2017.

MIURA, Priscila Miyuki. O reconhecimento das obras de Artigas pelo Condephaat. In: SEMINÁRIO DOCOMOMO BRASIL, 10, 2013, Curitiba. Disponível em: http://docomomo.org. br/course/10o-seminario-docomomo-brasil/. Acesso em: 13 dez. 2018.

MOTTA, Lia. Patrimônio urbano e memória social: práticas discursivas e seletivas de preservação cultural, 1975 a 1990. Dissertação (Mestrado) - Memória Social e Documento UniRio, Rio de Janeiro, 2000.

NASCIMENTO, Flávia Brito do. Blocos de memórias: habitação social, arquitetura moderna e patrimônio cultural. São Paulo: Edusp/Fapesp, 2016b.

NASCIMENTO, Flávia Brito do. Corredor Cultural do Rio de Janeiro: debates e combates pelo patrimônio cultural urbano nos anos 1970. Revista Patrimônio e Memória, 2018 (no prelo).

NASCIMENTO, Flávia Brito do. Formar e questionar? Os cursos de especialização em patrimônio cultural nos anos 1970. Anais do Museu Paulista, v. 24, p. 205-236, 2016 a.

NASCIMENTO, Flávia Brito do; MARINS, Paulo Cesar Garcez. Dossiê - O PCH, Programa de Cidades Históricas: um balanço após 40 anos - Introdução. Anais do Museu, v. 24, p. 11-14, 2016. 
NIGRO, Cintia. Territórios do patrimônio: tombamentos e participação social em São Paulo. Dissertação (Mestrado) - Programa de Geografia Humana FFLCH USP, São Paulo, 2001.

OKSMAN, Silvio. Contradições na preservação da arquitetura moderna. 2017. Tese (Doutorado) - História e Fundamentos da Arquitetura e do Urbanismo. Faculdade de Arquitetura e Urbanismo, Universidade de São Paulo, São Paulo, 2017.

OKSMAN, Silvio. Parecer do Conselheiro Relator - Processo n. 72.974, Higienópolis. Condephaat, 12/12/2014.

PEREIRA, Eduardo Carlos. Parecer do Conselheiro Relator - Conjunto de obras de Vilanova Artigas. Condephaat, 11/08/2011.

PINHEIRO, M. L. B.. Trajetória das ideias preservacionistas no Brasil: as décadas de $1920 \mathrm{e}$ 1930. Revista do Patrimônio Histórico e Artístico Nacional, v. 1, p. 13-31, 2017.

REIS, Daniel Aarão. Ditadura e democracia no Brasil. Do golpe de 1964 à Constituição de 1988. Rio de Janeiro: Zahar, 2014.

RODRIGUES, Marly. Imagens do passado: a instituição do patrimônio em São Paulo, 1969-1987. São Paulo: Unesp/Imprensa Oficial do Estado/Condephaat/Fapesp, 2000.

RUBINO, Silvana. O mapa do Brasil passado. Revista do Serviço do Patrimônio Histórico e Artístico Nacional, Rio de Janeiro, n. 24, p. 97-105, 1996.

SCIFONI, Simone. A construção do patrimônio natural. Tese (Doutorado) - Geografia Humana FFLCH/USP. São Paulo, 2006.

SEGAWA, Hugo. Arquiteturas no Brasil: 1900-199o. São Paulo: Edusp, 1998.

SMITH, Laurajane. Uses of heritage. New York: Routledge, 2006.

STIVAL SOARES, M. J. O plano de revitalização do setor histórico de Curitiba: conceitos, referências e conflitos na concepção do patrimônio urbano local. In: Anais do V Encontro Internacional sobre Preservação do Patrimônio Edificado - Arquimemória. Salvador: Departamento da Bahia do Instituto dos Arquitetos do Brasil, 2017.

TINEM, Nelci. O alvo do olhar estrangeiro: o Brasil na historiografia da arquitetura moderna. João Pessoa: Editora Universitária, 2006.

TONASSO, Mariana C. P. O patrimônio ambiental urbano e sua relação com os instrumentos urbanísticos de preservação na cidade de São Paulo. Revista CPC, São Paulo, n. 23, p. 12-39, ago. 2017.

TOURINHO, Andréa de Oliveira; RODRIGUES, Marly. Patrimônio ambiental urbano: uma retomada. Revista CPC, São Paulo, n. 22, p. 70-91, dez. 2016.

WOLFF, Silvia Ferreira Santos; ZAGATO, José Antonio Chinelato. A preservação do patrimônio moderno no Estado de São Paulo pelo Condephaat. Arquitextos, São Paulo, ano 17, n. 194.07, jul. 2016. Disponível em: http://www.vitruvius.com.br/revistas/read/arquitextos/17.194/6129. Acesso em: 13 dez. 2018.

WOLFF, Silvia. Arquitetura moderna - a preservação oficial. In: SEMINÁRIO DOCOMOMO, 1, São José dos Campos, 1998. 